\title{
Transurethral Resection and Surveillance of Bladder Cancer Supported by 5-Aminolevulinic Acid-Induced Fluorescence Endoscopy
}

\author{
Martin Kriegmair Dirk Zaak Helmut Stepp Herbert Stepp \\ Reinhold Baumgartner Ruth Knuechel Alfons Hofstetter \\ Department of Urology, University of Munich, and Institute of Pathology, University of Regensburg, Germany
}

\section{Key Words}

5-Aminolevulinic acid · Fluorescence $\cdot$ Bladder neoplasm

\begin{abstract}
Purpose: We determined whether neoplastic disease, which was missed under white light can be found during transurethral resection of bladder cancer by 5-aminolevulinic acid-induced porphyrin fluorescence. Materials and Methods: 5-Aminolevulinic acid-induced fluorescence endoscopy was carried out in 328 cases. A $3 \%$ 5-aminolevulinic acid solution was instilled intravesically in a mean time of $2.8 \mathrm{~h}$ before endoscopy. The fluorescence was excited by a special incoherent light source which provided blue light in addition to white light. Results: In 82 (25\%) cases additional neoplastic lesions were found only because of their red porphyrin fluorescence which was induced by 5 -aminolevulinic acid. $31 \%$ of these neoplastic foci which were found in normal and nonspecific inflamed mucosa had a poorly differentiated histology. Conclusions: 5-Aminolevulinic acid facilitates detection of neoplastic disease during transurethral resection of bladder cancer and increases the accuracy of diagnosis.
\end{abstract}

\section{Introduction}

Flat transitional cell carcinoma with insignificant enhancement of the urothelium and neoplastic lesions like dysplasia or carcinoma in situ without thickening of the epithelium can easily be missed during transurethral resection [1]. Thus, methods for in vivo marking of urothelial cancer have been sought [2-5]. We have applied a method for fluorescence marking of urothelial neoplasia of the bladder, which is based on intravesical application of 5-aminolevulinic acid (5-ALA) [6]. 5-ALA is an initial substrate of the heme biosynthesis. Exogenous application of 5-ALA induces an accumulation of fluorescent porphyrins mainly protoporphyrin IX (PPIX) in tissues of epithelial origin [7].

Using a krypton ion laser $(\lambda=406.7 \mathrm{~nm})$ for fluorescence excitation, we have previously reported that the 5-ALA-induced fluorescence is significantly correlated with neoplastic findings [6], including a low or negative PPIX fluorescence in adjacent stromal cells, as shown by fluorescence histology of sections [8]. However, the spread of the procedure was impaired because of the large-scale laser technology and the price of 5-ALA. The krypton ion laser was replaced by a special incoherent diagnosis light system (D-light, Storz GmbH, Tuttlingen, Germany). We report on our first clinical experience with 5-ALA-induced fluorescence endoscopy (AFE) for detection of primary and recurrent bladder cancer using the D-light.

\section{KARGER \\ Fax +4161306 1234 \\ E-Mail karger@karger.ch} www. karger.com (c) 1999 S. Karger AG, Basel

0302-2838/99/0365-0386\$17.50/0

Accessible online at:

http://BioMedNet.com/karger
Priv.-Doz. Dr. med. Martin Kriegmair

Karwendelstrasse 6

D-85604 Pöring (Germany)

Tel. +498106303 010, Fax +498106303011

E-Mail Kriegmair@uro.med.uni-muenchen.de 


\section{Materials and Methods}

\section{Patients}

A total of 208 patients underwent 328 5-ALA-induced fluorescence endoscopies. 72 patients were inspected for primary bladder cancer, and 136 patients were under surveillance because of prior transitional cell carcinoma of the urinary bladder. The age range of the patients ( 38 women and $170 \mathrm{men}$ ) in which fluorescence endoscopy was carried out was $16-89$ years with an average age of 64.8 years. The number of AFE per patient ranged from 1 to 7 with a medium of 1.6. The average time of follow-up was 11.1 months (range 1-29 months).

The patients which were previously treated for bladder cancer had a history of multiple transurethral resections (range 1-20, average 3.5) and intravesical instillations with BCG (50 patients) or Mitomycin C (49 patients).

5-ALA Administration. $1.5 \mathrm{~g}$ of 5-aminolevulinic acid hydro-chloride (Medac $\mathrm{GmbH}$, Hamburg, Germany) dissolved in $50 \mathrm{ml} \mathrm{1.4 \%}$ $\mathrm{NaHCO}_{3}$ was instilled intravesically with a $14 \mathrm{~F}$ catheter $2-3 \mathrm{~h}$ prior to endoscopy. The catheter was removed immediately after instillation. The $\mathrm{pH}$ value of the solution was 4.9. The solution was freshly prepared immediately before instillation and passed through a $0.2-\mu \mathrm{m}$ filter to eliminate pyrogens. The individual intravesical retention ranged from 0.5 to $5.5 \mathrm{~h}$ (average $2.8 \pm 1.4$ ). 12 patients voided within $1 \mathrm{~h}$ after intravesical instillation of the 5-ALA solution and were excluded from evaluation.

Fluorescence Excitation. The D-light (Storz $\mathrm{GmbH}$ ) provides blue light (375-440 nm) for fluorescence excitation of PPIX. A yellow longpass filter fit into the eyepiece of the endoscope reduces the blue excitation light and enhances the fluorescence contrast. In order to keep the transmission of the blue excitation light minimal the fiberoptic light cord was integrated into the telescope (30-degree lens). Switching between blue and white light is possible by means of a foot pedal.

\section{Fluorescence Endoscopy}

In 288 patients, a bladder washing with $100 \mathrm{ml} 0.9 \%$ sodium chloride solution was carried out at the beginning of endoscopy before AFE. In all cases endoscopy started with carefull inspection under white light. Particular attention was paid, whether tumors detected with white light during endoscopy showed red fluorescence under blue-light excitation. The number and location of tumors under white light were recorded. The endoscopy was continued under blue excitation light and all and all fluorescing lesions were documented. Special attention was paid whether these lesions were detected under white light or not. The procedure went on with resection of all exophytic lesions by means of a $24 \mathrm{~F}$ continuous flow endoscope (Storz $\mathrm{GmbH})$. In addition, biopsies from fluorescing areas, which appeared to be normal or nonspecifically inflamed were taken, and an attempt was made to resect or coagulate these flat lesions. Also, specimens were obtained with the electrical cutting loop from suspicious areas which were fluorescence negative. The fluorescence of the lesions was judged at the extended urinary bladders which were free of folds. Resection of tumors was carried out with the naked eye or with support of a special RGB-endocamera (Telecam SL, Storz $\mathrm{GmbH}$ ). The controller of the one-chip charge coupled device camera is equipped with a frame store, enabling target integration. 15 or 8 frames per second were used most frequently. The optical transmission to the red channel had been optimized and the sensitivity balance of the colors can be performed independently for white light and blue fluorescence excitation light.

Transurethral Resection and Surveillance of Bladder Cancer Supported by

5-ALA-Induced Fluorescence Endoscopy

\section{Evaluation of Data}

Results of AFE are described in a per patient fashion. Low-grade dysplasias were judged as benign. If lesions with different gradings were found the worst diagnosis was taken into account.

\section{Results}

Papillary urothelial cancer and carcinoma in situ developed a brilliant red fluorescence (fig. 1). In contrast, the adjacent normal nonfluorescent urothelium appeared blue. In table 1, the results of the $328 \mathrm{AFE}$ are listed. In 159 AFE, neoplastic lesions were resected or biopsied. In 82 AFE, additional dysplastic or malignant urothelium was found only because of the red PPIX fluorescence. 39 of these $82 \mathrm{AFE}$ had been carried out in patients who were inspected for primary bladder cancer, whereas 43 cases had a history of bladder cancer. In 97 AFE only fluorescing benign biopsies had been taken. 48 AFE were managed without biopsies because of complete fluorescencenegative findings and normal findings in white light. In another $20 \mathrm{AFE}$ without papillay tumors, the mucosa of the bladder was completely red fluorescence-negative. However, biopsies from suspicious areas under white light were taken in these. None of these biopsies revealed neoplastic disease. In 4 patients $\mathrm{pT}_{\mathrm{a}} \mathrm{G}_{\mathrm{I}}$ tumors were observed under white light which did not fluoresce in AFE.

Table 2 demonstrates the cases in which only normal or nonspecific inflammatory lesions were detected at white light endoscopy. The patients reported in table 3 represent the group which showed exophytic tumors at white light endoscopy. The sole detection of tumorous lesions by red PPIX fluorescence in the two groups shown in tables 2 and 3 can be summed up with the following numbers: dysplasias were detected in $24 \mathrm{AFE}$, carcinoma in situ (CIS) in 22, high-grade papillary TCC was discovered in 4, and papillary lesions of moderate and low differentiation in 32 AFE. Of 22 patients with CIS, 16 patients had additional flat dysplastic lesions and 3 patients showed $\mathrm{T}_{\mathrm{a}} \mathrm{G}_{\mathrm{I}-\mathrm{II}}$ lesions. In none of the 4 patients with $\mathrm{T}_{\mathrm{a}-1} \mathrm{G}_{\mathrm{III}}$ tumors was CIS found.

In the group of patients without exophytic tumors 29 patients presented a cytology positive or suspicious for disease. In 14 cases the cytological findings were verified by AFE detecting the precise site of malignancy within the bladder. Despite negative cytology, moderate dysplasia, CIS, high-grade superficial urothelial cancer and low-tomoderately differentiated superficial cancer were detected in 13, 4, 3 and $11 \mathrm{AFE}$, respectively, only because of their red porphyrin fluorescence. 15 patients had a positive cytology, however, no neoplastic biopsies were found 

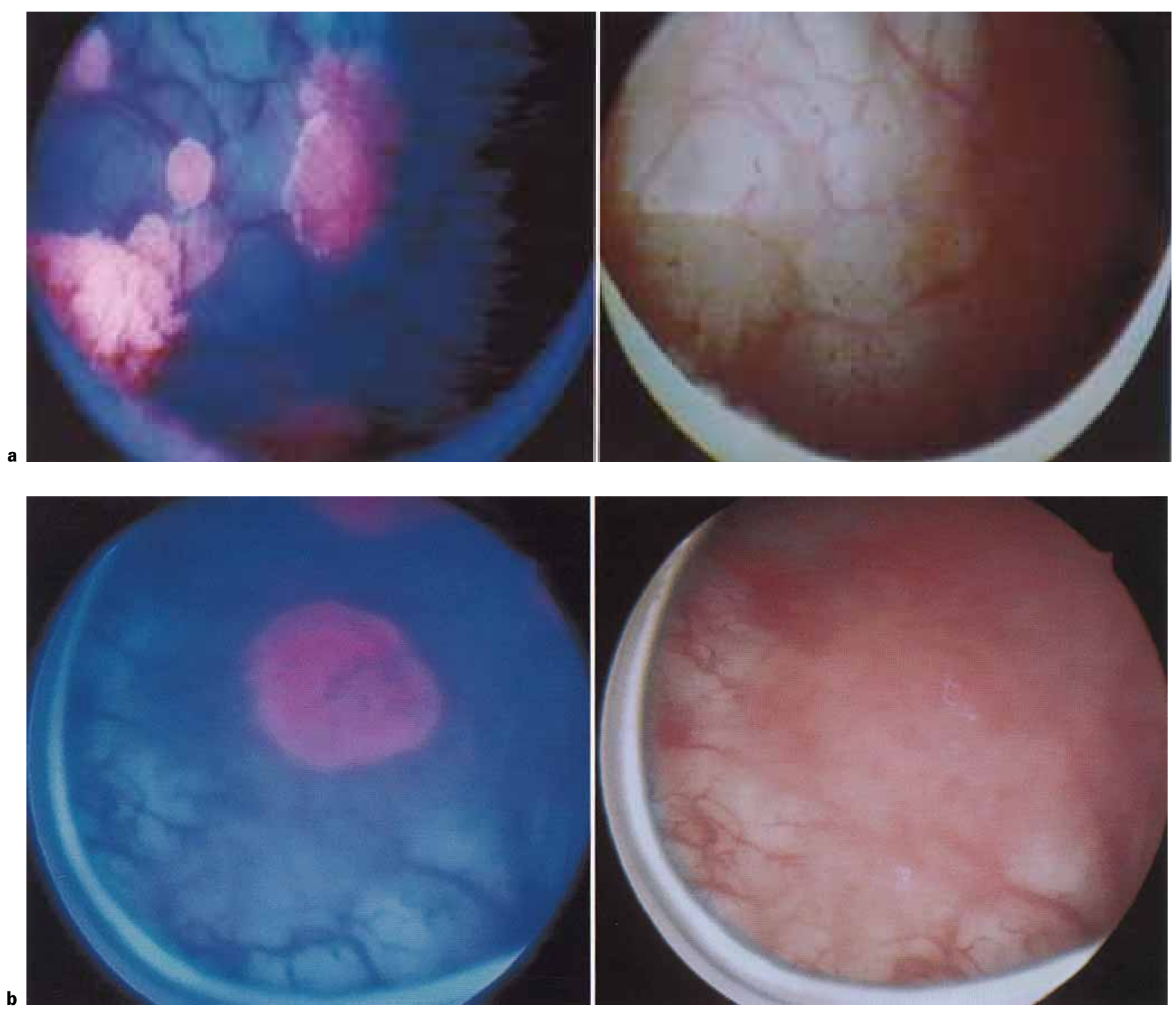

Fig. 1. a Endoscopic view of red fluorescing multifocal papillary tumors in contrast to their appearance under white light. Reduced from $\times 5$. b Endoscopic view of a red fluorescing lesion of carcinoma in situ in contrast to its appearance under white light. Reduced from $\times 8$.

within the bladder by AFE. In all these cases neoplastic disease of the upper urinary tract was excluded by a retrograde pyelography and washing cytology of the renal pelvis. Details on these findings are given in table 4 . In 4 of 13 patients with a cytological diagnosis of moderate dysplasia, disease was verified histologically under further surveillance by AFE-guided biopsies. Two cases with flat $\mathrm{T}_{\mathrm{a}} \mathrm{G}_{\mathrm{I}-\mathrm{II}}$ tumors and two with CIS were found. In 2 pa- tients cytological diagnosis was high-grade dysplasia. In 1 patient with a follow-up of 10 months, no neoplastic lesion has been localized so far. In the other patient a small moderately dysplastic lesion was found 8 months later by AFE-guided biopsies. Local or systemic side effects especially cutaneous photosensitization due to the instillation of 5-ALA and the use of blue light for fluorescence excitation were not observed. 
Table 1. Final results of the 5-aminolevulinic acid-induced fluorescence endoscopy findings

\begin{tabular}{|c|c|c|c|}
\hline \multicolumn{2}{|c|}{ AFE } & \multirow{2}{*}{$\begin{array}{l}\text { Number of } \\
\text { resected areas } \\
\text { range/average }\end{array}$} & \multirow[t]{2}{*}{ Result of AFE } \\
\hline $\mathrm{n}$ & $\%$ & & \\
\hline 77 & 23 & $1-10 / 2.6$ & $\begin{array}{l}\text { all neoplastic lesions detected were fluorescence positive } \\
\text { but were visible under white light }\end{array}$ \\
\hline 82 & 25 & $1-11 / 4.1$ & $\begin{array}{l}\text { neoplastic lesions were detected additionally only because } \\
\text { of red PPIX fluorescence signal }\end{array}$ \\
\hline 97 & 30 & $1-7 / 2.2$ & all fluorescing lesions biopsied were benign \\
\hline 48 & 15 & $0 / 0$ & $\begin{array}{l}\text { the complete urothelium of the bladder was fluorescence } \\
\text { negative, no biopsies were taken }\end{array}$ \\
\hline 20 & 6 & $1-10 / 1.5$ & $\begin{array}{l}\text { the complete urothelium of the bladder was fluorescence } \\
\text { negative; all biopsies taken were benign }\end{array}$ \\
\hline 4 & 1 & $1-5 / 1.9$ & $\begin{array}{l}\text { the complete urothelium of the bladder was fluorescence } \\
\text { negative; additionally fluorescence-negative small } \\
\text { papillary tumors were found }\end{array}$ \\
\hline 328 & 100 & $0-11 / 2.2$ & total \\
\hline
\end{tabular}

\begin{tabular}{llllll}
\hline Bladder washing & \multirow{2}{*}{$\begin{array}{l}\text { Total } \\
\text { cytology }\end{array}$} & \multicolumn{4}{l}{$\begin{array}{l}\text { AFE with neoplastic disease detected only } \\
\text { because of positive fluorescence }\end{array}$} \\
\cline { 3 - 6 } & & Dys II & Cis & $\mathrm{T}_{\mathrm{a}-1} \mathrm{G}_{\mathrm{III}}$ & $\mathrm{T}_{\mathrm{a}-1} \mathrm{G}_{\mathrm{I}-\mathrm{II}}$ \\
\hline Positive & 59 & 4 & 11 & - & 17 \\
Negative & 88 & 3 & 2 & 2 & 10 \\
Not done & 20 & 1 & - & - & 3 \\
\hline
\end{tabular}

Table 2. Detection of additional neoplasias in flat lesions, solely due to the positive PPIX fluorescence in patients with exophytic tumors

Table 3. Detection of additional neoplasias in flat lesions, solely due to the positive PPIX fluorescence in patients with normal or nonspecific inflammed mucosa

Table 4. Outcome of 15 patients with complete fluorescence negative findings during the initial AFE

Transurethral Resection and Surveillance of

AFE with neoplastic disease detected only because of positive fluorescence

\begin{tabular}{lccccc}
\multirow{2}{*}{$\begin{array}{l}\text { Bladder washing } \\
\text { cytology }\end{array}$} & $\begin{array}{l}\text { Total } \\
\text { AFE }\end{array}$ & \multicolumn{4}{l}{$\begin{array}{l}\text { AFE with neoplastic disease detected only } \\
\text { because of positive fluorescence }\end{array}$} \\
\cline { 3 - 6 } & & Dys II & Cis & $\mathrm{T}_{\mathrm{a}-1} \mathrm{G}_{\mathrm{III}}$ & $\mathrm{T}_{\mathrm{a}-1} \mathrm{G}_{\mathrm{I}-\mathrm{II}}$ \\
\hline Positive & 29 & 6 & 6 & 1 & 1 \\
Negative & 112 & 10 & 2 & 1 & 1 \\
Not done & 20 & - & 1 & - & - \\
\hline
\end{tabular}

\begin{tabular}{|c|c|c|c|c|c|c|}
\hline \multirow{3}{*}{$\begin{array}{l}\text { Bladder washing } \\
\text { cytology }\end{array}$} & \multirow[t]{3}{*}{ Patients } & \multirow{3}{*}{$\begin{array}{l}\text { Follow-up } \\
\text { months }\end{array}$} & \multicolumn{4}{|c|}{ Outcome of patients } \\
\hline & & & \multirow[t]{2}{*}{ NED } & \multicolumn{3}{|c|}{ positive AFE-guided biopsies } \\
\hline & & & & Dys II & $\mathrm{T}_{\mathrm{a}} \mathrm{G}_{\mathrm{I}-\mathrm{II}}$ & Cis \\
\hline \multirow{2}{*}{$\begin{array}{l}\text { Moderate dysplastic } \\
\text { High-grade dysplastic or } \\
\text { carcinoma in situ }\end{array}$} & 13 & $5-18$ & 9 & - & 2 & 2 \\
\hline & 2 & 8,10 & 1 & 1 & - & - \\
\hline
\end{tabular}




\section{Discussion}

The risk of overlooking neoplastic lesions of the bladder using white-light endoscopy is significant. After transurethral resection of superficial bladder cancer, tumor remnants were found in up to $43 \%$ of the cases at repeated resection 1-2 weeks later [9-11]. Even in the case of solitary superficial bladder tumors residual disease was found in $24 \%$ at a second transurethral resection 5 weeks later [11]. The authors underlined the quality of their first resection by the fact that the second resection revealed infiltrative growth in only $2 \%$ of the cases. Therefore, most of this overlooked neoplasms came from positive margins or heterotopic lesions.

Klän et al. [9] reported on a fractionated resection of $\mathrm{T}_{1}$ transitionall cell cancer. In $28 \%$ of the patients positive tumor margins were found while residual disease from the tumor base was not observed in any case. A routine second resection was carried out 8-14 days later and revealed residual disease in $50 \%$ of the patients despite the surgical report of complete resection. $76 \%$ of the missed lesions were found to be visible tumors at the repeated resection. The authors concluded that the extent of the lesions can easily be misjudged even by experienced surgeons. AFE was very helpful in finding residual tumor at the end of the transurethral resection. Especially the borderline of a tumor was more clearly visible than it was under white light. Neoplastic lesions in the surroundings of exophytic tumors which appeared normal or nonspecifically inflamed were marked by brightly shining red PPIX fluorescence. In the case of multiple tumors, the spots of neoplastic disease were found more easily and more promptly by AFE compared to white-light endoscopy alone.

Fitzpatrick et al. [12] reported on 414 newly diagnosed patients with $\mathrm{pT}_{\mathrm{a}} \mathrm{G}_{\text {I-II }}$ tumors. Patients who underwent intravesical therapy during their follow-up were excluded from this study. In one third of the patients recurrent, or more likely residual, disease was found 3 months after the initial resection. $90 \%$ of these patients had further recurrences thereafter, whereas only $21 \%$ of the patients who were free of tumor 3 months after the initial resection demonstrated recurrent tumor during further follow-up. The response to the initial treatment of superficial bladder cancer for the outcome of the patients has also been stressed as relevant by Pryor. [13]. Therefore, a complete removal of tumorous lesions from the bladder seems advisable. Especially flat lesions as CIS which may be concealed in the nonspecific inflamed or normal-appearing mucosa are of crucial effect on the rates of progression and recurrence and require adequate intravesical immunotherapy without delay [14-16]. Random biopsies were found to be an insufficient method for detecting flat lesions $[17,18]$. In a retrospective study Kiemeney et al. [17] found no correlation between patient outcome where selected mucosal biopsies were not performed or, if done, were normal. However, if dysplasia or CIS were found in patients, they had a statistically significant higher risk of tumor progression. Therefore, random biopsies seem to be inadequate since relevant early stage and precancerous lesions are often missed. Cytology of voided urine or bladder washings are valuable for the diagnosis, especially of high-grade lesions. However, recent prospective trials have resulted in a disappointingly low sensitivity of 54\% for detecting CIS [19]. Using white-light endoscopy, the detection of neoplasms is limited to morphological patterns. Since the 1960s, urologists have sought for methods of in vivo labeling neoplastic lesions in order to decrease the risk of overlooking tumors by the help of an additional color contrast.

Methods based on detection of the fluorescence of systemically administered tetracycline, systemic porphyrin mixtures or fluorescein have only been tested in a few patients and have been abandonned. Intravesical instillation of methylene blue was also proven unsuitable, since $70 \%$ of CIS and $84 \%$ of dysplastic lesions were not stained [4].

We have been investigating 5-ALA for detection of urothelial cancer since 1991. 5-ALA is a precursor of the heme biosynthesis and induces an accumulation of fluorescent endogenous porphyrins, mainly protoporphyrin IX (PPIX) in tissues of epithelial origin [7]. Following intravesical application of 5-ALA, we could demonstrate a selective accumulation of PPIX in urothelial cancer providing an intensive color contrast between red fluorescing malignant lesions and the nonfluorescing normal blue mucosa [6]. Spectral measurements in vivo showed a more than 10-fold higher intensity of fluorescence of urothelial cancer in comparison to normal urothelium [20]. Due to the topical mode of administration of 5-ALA and the fast metabolism, only minor side effects such as urgency and alginuresis were observed in $7 \%$ of the cases $[21,23]$.

Initially, a krypton ion laser was used for fluorescence excitation. Based on a biopsy-related evaluation, we reported a significant increase in sensitivity for the diagnosis of neoplastic urothelial lesions such a dysplasia and CIS as well as for papillary tumors by the additional evaluation of the porphyrin fluorescence. In total, the procedure was marked by a sensitivity of $96 \%$ and a specificity of $65 \%$ [21]. 
The outstanding sensitivity of the procedure was confirmed by the investigations of Jichlinski et al. [22]. Using this method of fluorescence detection they found 47 of 97 foci of carcinoma only by fluorescence markings which were invisible under white-light observation and concluded that the sensitivity of the method appears to be twice as good as conventional white-light cystoscopy. The largescale laser technology for excitation of the PPIX fluorescence was replaced by the D-light ${ }^{\circledR}$ which is a specially designed incoherent diagnosis light system. This equipment meets all the requirements for a daily routine procedure and can be used in combination with standard urological endoscopes. Based on a per patient fashion, we found that the patients had a benefit in 150 of $328 \mathrm{AFE}$ cases $(45 \%)$. In 82 cystoscopies additional neoplastic lesions were found which would have been missed under white-light observation alone. In 68 cases of complete fluorescence negative mucosa no biopsies would have been necessary due to the high sensitivity of the procedure. $31 \%$ of the malignant foci which were found only because of their positive PPIX fluorescence signal in the normalappearing or nonspecific inflamed mucosa were high-risk lesions such as carcinoma in situ or poorly differentiated papillary tumors. In $30 \%$ of the AFE, exclusively falsepositive findings were observed. This seems to be acceptable as in total the mean number of biopsies was low with 2.2 per patient. No matter how, it is obviously significantly less than the number of random biopsies carried out under white light. False-positive responses were frequently found in lesions with increased cellular proliferation due to inflammation or scarring. However, these lesions apparently showed a lower fluorescence intensity. Therefore, methods for fluorescence quantification have been established and are now under investigation in order to reduce the rate of false-positive biopsies [24]. Further, false-positive lesions as simple hyperplasias have shown to already have genetic changes identical to those of papillary tumors of the same patient [25]. This result indicates that at least part of the false-positive lesions are tumor precursors and is investigated intensively in longitudinal and horizontal studies of patient material.

There is a bad correlation between cytology and AFE. However, cytology and AFE are not competitive methods as cytology is a noninvasive and AFE is an invasive procedure. AFE can help clarify suspicious cytological findings and therefore AFE-guided biopsies and cytology seem to be complementary methods for accurate diagnosis of bladder cancer. In 14 of 112 patients who had no exophytic tumors and had a negative cytology, a neoplastic lesion was found in fluorescing areas of the bladder wall. In 5 of 15 patients with complete negative fluorescing mucosa but positive cytology, neoplastic disease was found later due to positive AFE-guided biopsies during follow-up of these patients.

\section{Conclusions}

5-Aminolevulinic acid-based fluorescence endoscopy facilitates detection of neoplastic lesions within the bladder during transurethral resection. In case of complete negative fluorescence findings, endoscopy can be done without biopsies due to the high sensitivity of the procedure. A decrease of the rate of overlooked tumors is expected for transurethral resection supported by 5 -aminolevulinic acid-induced fluorescence endoscopy. A resulting relatively decreased number of recurrences has to be documented in prospective randomized trials.

\section{Acknowledgement}

Supported by grants from the Deutsche Forschungsgemeinschaft (DFG No. Kr1645/1-1).

\section{References}

1 Soloway MS, Murphy W, Rao MK, Cox C: Serial multiple-site biopsies in patients with bladder cancer. J Urol 1978;120:57-59.

2 Whitmore WF Jr, Bush IM: Ultraviolet cystoscopy in patients with bladder cancer. Trans Am Assoc Genitourin Surg 1965;57:149-155.

3 Jocham D, Baumgartner R, Fuchs N, Lenz H, Stepp H, Unsöld E: Fluorescence diagnosis of porphyrin-marked urothelial tumors: Status of experimental development. Urologe [A] 1989; 28:59-64.
4 Vicente J, Chechile G, Algaba F: Value of in vivo mucosa-staining test with methylene blue in the diagnosis of pretumoral and tumoral lesions of the bladder. Eur Urol 1987;13:1516.

5 Zimmern PE, Laub D, Leach GE: Fluorescein angiography of the bladder: technique and relevance to bladder cancer and interstitial cystitis patients. J Urol 1995; 154:62-65.
6 Kriegmaier M, Baumgartner R, Knuechel R, Steinbach P, Ehsan A, Lumper W, Hofstaedter F, Hofstetter A: Fluorescence photodetection of neoplastic urothelial lesions following intravesical instillation of 5-aminolevulinic acid. Urology 1994;44:836-841.

7 Kennedy JC, Pottier RH: Endogenous protoporphyrin IX; a clinically useful photosensitizer for photodynamic therapy. J Photochem Photobiol [B] 1992;14:275-292. 
8 Steinbach P, Kriegmaier M, Baumgartner R, Hofstaedter F, Knuechel R: Intravesical instillation of 5-aminolevulinic acid: the fluorescent metabolite is limited to urothelial cells. Urology 1994;44:676-681.

9 Klän R, Loy V, Huland H: Residual tumor discovered in routine second transurethral resection in patients with stage $\mathrm{T} 1$ transitional cell carcinoma of the bladder. J Urol 1991;146: 316-318.

10 Vögeli TA, Grimm MO, Ackermann R: Prospective study for quality control of TUR of bladder tumors by routine 2 nd TUR. J Urol 1998;159(suppl):143.

11 Köhrmann KU, Woeste M, Kappes J, Rassweiler J, Alken P: Der Wert der transurethralen Nachresektion beim oberflächlichen Harnblasenkarzinom. Akt Urol 1994;25:208-213.

12 Fitzpatrick JM, West AB, Butler MR, Lane V, O'Flynn JD: Superficial bladder tumors (stage pTa, grades 1 and 2): The importance of recurrence pattern following initial resection. J Urol 1986;135:920-922.

13 Pryor JP: Factors influencing the survival of patients with transitional cell tumours of the urinary bladder. Br J Urol 1973;45:586-592.

14 Smith G, Elton RA, Beynon LL, Newsam JE, Chisholm GD, Hargreave TB: Prognostic significance of biopsy results of normal-looking mucosa in cases of superficial bladder cancer. Br J Urol 1983;55:665-669.
15 Heney NM, Ahmed S, Flanagan MJ, Frable W, Corder MP, Hafermann MD, Hawkins IR: Superficial bladder cancer: progression and recurrence. J Urol 1983;130:1083-1086.

16 Flamm J, Dona S: The significance of bladder quadrant biopsies in patients with primary superficial bladder carcinoma. Eur Urol 1989;2: 81-85.

17 Kiemeney LA, Witjes JA, Heijbroek RP, Verbeek AL, Debryune FM: Predictability of recurrent and progressive disease in individual patients with primary superficial bladder cancer. J Urol 1993;150:60-64.

18 Kiemeney LA, Witjes JA, Heijbroek RP, Koper NP, Verbeek AL, Debruyne FM: Should random urothelial biopsies be taken from patients with primary superficial bladder cancer? A decision analysis. Members of the Dutch South-East Co-Operative Urological Group. Br J Urol 1994;73:164-171.

19 Sarosdy MF, deVere White RW, Soloway MS, Sheinfeld J, Hudson MA, Schellhammer PF, Jarowenko MV, Adams G, Blumenstein BA: Results of a multicenter trial using the BTA test to monitor for and diagnose recurrent bladder cancer. J Urol 1995;154:379-384.

20 Kriegmair M, Stepp H, Steinbach P, Lumper W, Ehsan A, Stepp HG, Rick K, Baumgartner R, Hofstetter A: Fluorescence cystoscopy following intravesical instillation of 5-aminolevulinic acid: A new procedure with high sensitivity for detection of hardly visible urothelial neoplasias. Urol Int 1995;55:190-196.
21 Kriegmair M, Baumgartner R, Knuchel R, Stepp H, Hofstaedter F, Hofstetter A. Detection of early bladder cancer by 5-aminolevulinic acid induced porphyrin fluorescence. J Urol 1996;155:105-110.

22 Jichlinski P, Forrer M, Mizeret J, Glanzmann $\mathrm{T}$, Braichotte D, Wagnieres $\mathrm{G}$, Zimmer $\mathrm{G}$, Guillou L, Schmidlin F, Graber P, van den Bergh $\mathrm{H}$, Leisinger HJ: Clinical evaluation of a method for detecting superficial surgical transitional cell carcinoma of the bladder by lightinduced fluorescence of protoporphyrin IX following the topical application of 5-aminolevulinic acid: Preliminary results. Lasers Surg Med 1997;20:402-408.

23 Rick K, Sroka R, Stepp H, Kriegmair M, Huber RM, Jacob K, Baumgartner R: Pharmacokinetics of 5-aminolevulinic acid induced protoporphyrin IX in skin and blood. J Photochem Photobiol [B] 1997;40:313-319.

24 Kriegmair M, Wagner S, Stepp H, Hofstetter A: Fluoreszenzquantifizierung bei der 5-Aminolävulinsäure induzierten Fluoreszenzendoskopie des Harnblasenkarzinoms. Urologe [A] 1997;37:S50.

25 Knuechel R, Kutz H, Hofstaedter F, Hofstetter A, Kriegmair M: Photodynamic diagnostics with 5-ALA in bladder cancer: Biology of false positive lesions. Urol Res 1997;25:94-95. 